Research Article

Pavel Reiterman*, Ondřej Holčapek, Ondřej Zobal, and Martin Keppert

\title{
Freeze-Thaw Resistance of Cement Screed with Various Supplementary Cementitious Materials
}

https://doi.org/10.1515/rams-2019-0006

Received Nov 02, 2018; accepted Feb 08, 2019

\begin{abstract}
This paper describes a study of the effect of partial replacement of ordinary Portland cement (OPC) by various mineral additives in the screed mixtures. Ceramic powder, blast furnace slag and fly ash were gradually employed in increments of $12.5 \mathrm{wt} . \%$ up to $50 \mathrm{wt} . \%$ to replace OPC. The mixtures were designed to a constant consistency. The influence of mineral additives was evaluated in terms of the air content in the fresh mixtures, the compressive strength, the flexural strength and the freeze-thaw resistance and using non-destructive measurements after 28 and 90 days. The accompanied paste samples were analysed using thermogravimetry to monitor the hydration process by means of total bound water content. The decrease in the mechanical properties and the frost resistance of the mixtures with the mineral additives were recorded, because of the necessity for a larger addition of water. According to the valid standards for concrete screed related to the frost resistance, it could be concluded that maximal suitable cement replacement contents are 12.5, 37.5 and 50 wt.\% for ceramic powder, fly ash and blast furnace slag, respectively. The freeze-thaw resistance of the studied materials was found to be strongly related to the content of $\mathrm{CSH}$ and CAH hydrates.
\end{abstract}

Keywords: frost resistance; mechanical properties; chemically bound water

\footnotetext{
*Corresponding Author: Pavel Reiterman: University Centre for Energy Efficient Buildings, Czech Technical University in Prague, Třinecká 1024, Buštěhrad, 273 43, Czech Republic; Fakulty of Civil Engineering, Czech Technical University in Prague, Thákurova 7, Prague, 166 29, Czech Republic; Email: pavel.reiterman@fsv.cvut.cz Ondřej Holčapek: Fakulty of Civil Engineering, Czech Technical University in Prague, Thákurova 7, Prague, 166 29, Czech Republic Ondřej Zobal, Martin Keppert: University Centre for Energy Efficient Buildings, Czech Technical University in Prague, Třinecká 1024, Buštěhrad, 273 43, Czech Republic; Fakulty of Civil Engineering, Czech Technical University in Prague, Thákurova 7, Prague, 166 29, Czech Republic
}

\section{Introduction}

Incorporation of various mineral additives (Supplementary cementing materials, SCMs) into Portland cementbased composites is a generally well known and frequently used approach. These substances are usually employed for partial replacement of Portland clinker in the production of blended cements. The use of mineral additives (or blended binding systems) brings significant ecological and economic benefits [1-3].

Fly ash belongs among the most popular mineral additives used in the concrete industry to reduce the heat of hydration or to improve the consistency of fresh concrete. The use of fly ash is also beneficial for the durability and permeability properties; however, replacement exceeding $40 \mathrm{wt} . \%$ causes a significant reduction in the service life due to reduction of the $\mathrm{Ca}(\mathrm{OH})_{2}$ content and thus reduced natural level of protection of steel reinforcement. However, a binding system with high cement replacement by fly ash could be improved by the addition of ground limestone [4]. Studies focused on the freeze-thaw resistance yield a wide range of results, because fly ash has very variable properties and also because a relatively low carbon content results in a significant air-entraining effect resulting in improved freeze-thaw resistance. These aspects complicate definite assessment of the influence of fly ash on this durability property; however, there is, in general, a favorable effect of fly ash on the long-term durability of concrete [57].

Blast furnace slag (BFS) is a by-product formed during pig iron production. The incorporation of ground blast furnace slag into concrete is very beneficial because of its positive effect on the durability properties [8]. Blast furnace slag could be activated by $\mathrm{Ca}(\mathrm{OH})_{2}$ in cement or lime-based composites, but any other alkaline substances could be used. BFS belongs among "latent hydraulic materials", because of its $\mathrm{CaO}$ content, which allows considerably higher dosing compared with fly ash, silica fume and other pozzolans. BFS has a positive effect on a number of engineering properties, such as bleeding, consistency of the fresh mixture, the heat of hydration and the permeability. The relatively high bulk density of a cement ma- 
trix modified by slag frequently leads to a decrease in the frost resistance, however, the results of experimental studies are inconsistent [9-11]. This could be partly a result of the different experimental procedures and also because of the use of modifying agents such as plasticizers, which significantly affect the character of the porous system.

Ceramic powder is a relatively new mineral additive that has been studied in recent years; however its use dates back to ancient times $[12,13]$. The current intensive research on this substance is caused by the current lack of traditional additives, such as fly ash and blast furnace slag, or more precisely by the increase in their prices in developed countries. Significant motivation is also stimulated by the increasing amount of brick waste formed during demolition work $[14,15]$. In relation to the renovation of historical monuments, ceramic powder has been intensively studied for use in lime-based mortars. An in-depth study was carried out by Navrátilová and Rovnaníková [16], who studied the pozzolanic reactivity of ceramic powders and subsequently also selected engineering properties of limebased mortars. Previous research was focused on assessment of the influence of the particle size distribution on the reactivity, where was found that particles up to $0.030 \mathrm{~mm}$ make a predominant contribution to pozzolanic reaction. The significant effect of the ceramic powder fineness was also pointed out in $[16,17]$. Ceramic powder could be successfully employed as a replacement for cement in highperformance concrete (HPC) [18]; however, the high water absorption of clay brick powder limits its practical application with respect to the final frost resistance.

The frost resistance of concrete is a very important engineering property, which determines the service life of concrete structures. Deterioration of concrete by the action of frost is caused by the expansion of absorbed water when the temperature drops below $0^{\circ} \mathrm{C}$ and ice starts to form, which results in an increase in volume by about $9 \%[5,6]$. Internal stresses cause structural damage and the initiation of cracks, which accelerate the destruction. Air-entraining of the concrete is a commonly used method to improve the frost resistance. The resulting air bubbles form a reserve space where the ice can crystalize freely. However, only pores with a diameter of approximately 300 $\mu \mathrm{m}$ are effective. The recommended level of air-entraining is about $5 \%$, which already causes a reduction in the mechanical properties. It is necessary to compensate this loss by technological steps to retain the required class of the concrete. Deterioration of concrete by frost and surface scaling due to the combined action of frost and de-icing salts must be distinguished. An in-depth review dealing with the aspects of frost resistance was published by Glinicki et al. [19]. In general, the frost resistance is depen- dent on the actual content of water present in the concrete structure. Consequently, national standard CSN 73 1325 [20] used for indicative assessment of the frost resistance of concrete is based on simple gravimetric measurement of the water absorption after 10 and 1440 minutes, where the limiting values are 2.5 and $6.5 \%$, respectively.

The transport properties of concrete essentially depend on the character of the pore system [21, 22]; this fact also determines the behavior of concrete under action of frost. Absorbed water is fixed in the concrete by capillary forces, which are inversely proportional to the diameter of the capillaries [23, 24]. Expanding ice increases the hydraulic pressure in capillaries and damage could occur $[25,26]$. Consequently, a hydraulic pressure model is often used to numerically describe this process [27-30]. However, the process in question is directly proportional to the rate of temperature decrease $[25,31]$. In addition, forming crystals of ice could interact with the walls of the capillary pores. Air-entraining in the concrete provides effective protection because these voids provide space for the nucleation and crystallization of ice [25], however uniform spatial distribution of the air voids is a crucial aspect [28, 32]. A drawback of the Power's theory is the fact, that the thermal mismatch of individual constituents when the concrete is exposed to low temperatures is not taken into consideration.

In addition to the free water in capillary system, chemically bound water also affects the response of the concrete to freezing. The accompanying shrinkage during freezing also slightly increases the hydraulic pressure, but the deterioration could be substantially intensified during loading cycles. The response of concrete to cyclic freezing-thawing is controlled by a binder system, assuming application of a frost resistant aggregate. Balapour et al. [33] reviewed the effect of nano-silica fume compared with other SCMs on various technological properties. It was found that the freeze-thaw resistance corresponds to the content of insoluble hydrates in the cement paste. These findings were also reached by Behfarnia and Salemi [34], who described the beneficial impact of amorphous $\mathrm{Al}_{2} \mathrm{O}_{3}$. However, the used binder system also significantly affects the character of the concrete capillary system, which was studied in a previous work [35]. In general, modern concrete mixtures with reduced water to cement ratio exhibit increased frost resistance; nevertheless, this approach tends to increase the autogenous shrinkage, which could cause propagation of surface cracks during hardening in the case of a poor curing regime, resulting in reduction of the durability and especially the frost resistance [36]. The curing of the concrete, especially in the early stages, is a very important factor. Thermal effects of the solid phases and ice, hydraulic 
Table 1: Composition of studied concrete screeds [ $\left.\mathrm{kg} \mathrm{m}^{-3}\right]$.

\begin{tabular}{cccccccc}
\hline Mixture & CEM I 52.5 R [kg] & Fly ash $[\mathrm{kg}]$ & $\begin{array}{c}\text { Blast furnace } \\
\text { slag }[\mathrm{kg}]\end{array}$ & $\begin{array}{c}\text { Ceramic } \\
\text { powder }[\mathrm{kg}]\end{array}$ & $\begin{array}{c}\text { Silica sand } \\
0-4 \mathrm{~mm}[\mathrm{~kg}]\end{array}$ & Water [kg] & $\mathrm{w} / \mathrm{b}[-]$ \\
\hline Ref & 424 & 0 & 0 & 0 & 1680 & 232 & 0.55 \\
FA-12.5 & 371 & 53 & 0 & 0 & 1680 & 232 & 0.55 \\
FA-25.0 & 318 & 106 & 0 & 0 & 1680 & 237 & 0.56 \\
FA-37.5 & 265 & 159 & 0 & 0 & 1680 & 242 & 0.57 \\
FA-50.0 & 212 & 212 & 0 & 0 & 1680 & 232 & 0.55 \\
BS-12.5 & 371 & 0 & 53 & 0 & 1680 & 232 & 0.55 \\
BS-25.0 & 318 & 0 & 106 & 0 & 1680 & 232 & 0.55 \\
BS-37.5 & 265 & 0 & 159 & 0 & 1680 & 232 & 0.55 \\
BS-50.0 & 212 & 0 & 212 & 0 & 1680 & 232 & 0.55 \\
CP-12.5 & 371 & 0 & 0 & 53 & 1680 & 232 & 0.55 \\
CP-25.0 & 318 & 0 & 0 & 106 & 1680 & 253 & 0.60 \\
CP-37.5 & 265 & 0 & 0 & 159 & 1680 & 264 & 0.62 \\
CP-50.0 & 212 & 0 & 0 & 212 & 1680 & 274 & 0.65 \\
\hline
\end{tabular}

pressure and crystallization pressure act synergically synergistically? and thus it is difficult to accurately resolve the individual effects.

The present paper deals with screeds, i.e. cementitious composites with fine-grain aggregates, for use as a construction layer exposed to the environment. Thus, the freeze-thaw resistance of the screed is of primary importance. The influence of three SCMs partially replacing Portland cement in screed was tested and analyzed with respect to the chemically bound water content. No other admixtures were used in order to evaluate only the influence of the studied SCMs.

\section{Experimental program}

Sets of cement screeds with gradual replacement of Portland cement by various SCM were studied. The screed consisted of pure silica sand of the $0.063-4.0 \mathrm{~mm}$ fraction, Portland cement $52.5 \mathrm{R}$, water, and SCMs - fly ash, blast furnace slag and ceramic powder (Table 1). The chemical composition of the used binding components are shown in Table 2. Constant consistency of the fresh mixture was controlled by adjusting the amount of water. The consistency was adjusted to $135 \mathrm{~mm}$ of flow according to the methodology described below.

\section{Fresh screed}

Fresh cement screeds were prepared in a horizontal laboratory mixer. The consistency of the fresh mixture was deter-
Table 2: Chemical composition of used binding components [\%].

\begin{tabular}{ccccc}
\hline Component & $\begin{array}{c}\text { Ceramic } \\
\text { powder }\end{array}$ & $\begin{array}{c}\text { Blast } \\
\text { furnace } \\
\text { slag }\end{array}$ & Fly ash & $\begin{array}{c}\text { Portland } \\
\text { cement }\end{array}$ \\
\hline $\mathrm{SiO}_{2}$ & 50.7 & 36.0 & 52.4 & 18.5 \\
$\mathrm{Al}_{2} \mathrm{O}_{3}$ & 20.0 & 9.0 & 35.9 & 6.5 \\
$\mathrm{Fe}_{2} \mathrm{O}_{3}$ & 6.2 & 0.3 & 4.9 & 2.4 \\
$\mathrm{CaO}$ & 11.6 & 43.5 & 1.2 & 64.9 \\
$\mathrm{MgO}$ & 4.8 & 8.3 & 0.8 & 1.0 \\
$\mathrm{~K}_{2} \mathrm{O}$ & 3.2 & 0.5 & 1.4 & 1.2 \\
$\mathrm{Na}_{2} \mathrm{O}$ & 1.3 & 0.5 & - & 0.1 \\
$\mathrm{TiO}_{2}$ & 0.8 & 0.3 & 2.4 & - \\
$\mathrm{SO}_{3}$ & 1.0 & 0.5 & 0.2 & 4.9 \\
\hline
\end{tabular}

mined according to CSN EN 1015-3 [37] using Hagermann's flow table. The air content was measured using the pressure method according to CSN EN 12350-7 [38]; this is a significant property in determination of the final resistance to the freeze-thaw cycles.

\section{Hardened screed}

The bulk density, $\rho_{v}\left(\mathrm{~kg} / \mathrm{m}^{3}\right)$ was determined on the basis of the weight and accurate dimensions of the specimens. The flexural strength, $f_{t}(\mathrm{MPa})$, was measured on prismatic specimens with dimensions of $40 \times 40 \times 160 \mathrm{~mm}$. The test was organized as a three-point test with support span of $100 \mathrm{~mm}$ and axial loading. The compressive strength was determined on the fragments remaining after the flexural 
test on a marked loading area of $40 \times 40 \mathrm{~mm}$. Both tests were conducted using loading machine EU 40.

The frost resistance test of the studied concrete mixtures was performed according to CSN 731322 [39] using the above-described prisms. The frost resistance was expressed in terms of an index based on the performance ratios of both the residual and the original investigated values of the flexural strength. The load cycle began with a four-hour frosting phase at $-18^{\circ} \mathrm{C}$, followed by a twohour defrosting period up to $20^{\circ} \mathrm{C}$. Defrosting was accomplished by flooding the climatic chamber with water $\left(20^{\circ} \mathrm{C}\right)$. This standard procedure was also used in [40].

The ultrasonic pulse method was used to assess the dynamic modulus of elasticity $E_{c y}[\mathrm{GPa}$, which was monitored predominantly during freeze-thaw cycling. This method was performed according to standard CSN 731371 [41].

\section{Thermogravimetry}

A set of $40 \times 40 \times 160 \mathrm{~mm}$ paste prisms with the corresponding composition was prepared for each mixture; the pastes were made with the relevant binding components and appropriate w/c. These samples were cured under wet conditions. Thermogravimetry analysis was carried out on approximately $50 \mathrm{mg}$ of the ground powder by monitoring the weight loss in the range $105-1000^{\circ} \mathrm{C}$ after 24 hours, 28 and 90 days. The DTA-TG measurement (Schimadzu DTG$60 \mathrm{H})$ was carried out in an air atmosphere with a heating rate of $10^{\circ} \mathrm{C} / \mathrm{min}$. The amount of chemically bound water (H) and calcium hydroxide (CH) were expressed as wt.\% of the dry sample, according to Eq. 1 and Eq. 2. The exact boundaries of decomposition were read from the derivative curves (DTG). A similar procedure was used in [42, 43]. The amount of water bound in the $\mathrm{CSH}$ and $\mathrm{CAH}$ hydrates was calculated as the difference between the total amount of bound water and the water bound in portlandite (Eq. 3).

$$
\begin{gathered}
H=\frac{w_{105}-w_{550}}{w_{550}} \\
C H=\frac{w_{450}-w_{550}}{w_{550}} \cdot \frac{74}{18} \\
H_{\text {hyd }}=H-H_{C H}
\end{gathered}
$$

$\left.{ }^{\star}\right) 74 / 18$ is the ratio of molar weight of decomposed $\mathrm{Ca}(\mathrm{OH})_{2}$ and water $\mathrm{H}_{2} \mathrm{O}$.

\section{Results and Discussion}

Sets of cement based screeds with various replacement by SCM were studied in the experimental program. The individual mixtures were designed to constant consistency, which was controlled by addition of water to flow of 135 mm. As documented in Table 1, mixtures with 25.0 and $37.5 \%$ of fly ash required additional amount of water. On the other hand, replacement by blast furnace slag did not require any additional water. When ceramic powder was used, constant water dosage was reached only for the lowest level of replacement. A gradual increase in the amount of ceramic powder in the mixture required the addition of more water. These results correspond to the previous results [44], related to the above-mentioned greater water adsorption of the ceramic particles.

The use of SCMs significantly affected the content of air in the fresh concrete, where the control mixture and the mixture with lowest fly ash content exhibited the highest value of $6.1 \%$, which is clearly visible in Figure 1 . The used mineral additives favourably complemented the mixture grading, leading to better filling of the intergranular space and decreased air content in the fresh mixture. A gradual reduction in the air content with increasing replacement rate can be observed for all the studied mineral additives; however, this decrease was very slight for ceramic powder.

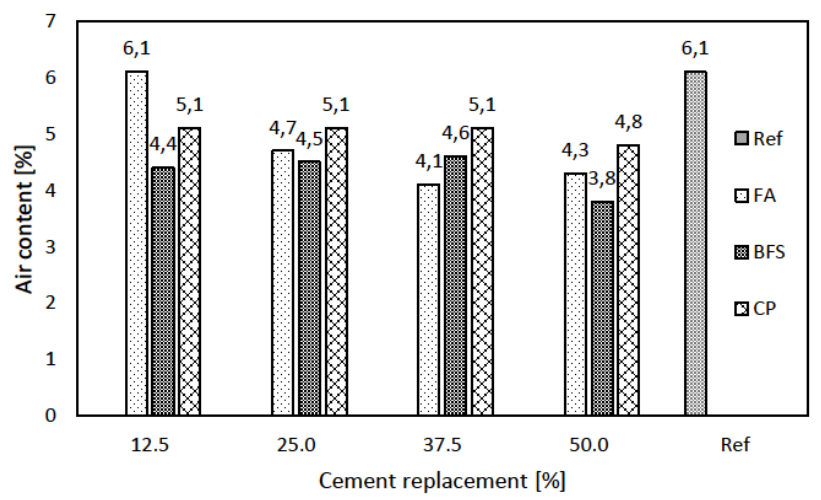

Figure 1: Air content in fresh mixtures [\%].

The positive effect of the lower dosage of mineral additives is apparent from the bulk density results after 90 days (Figure 2). These values are also significantly affected by the additional dose of mixing water, what well documents the curve of the blast furnace slag, where it was not necessary to increase the water addition to maintain a constant consistency. As expected, the mixtures with replacement by ceramic powder exhibited, according to expecta- 


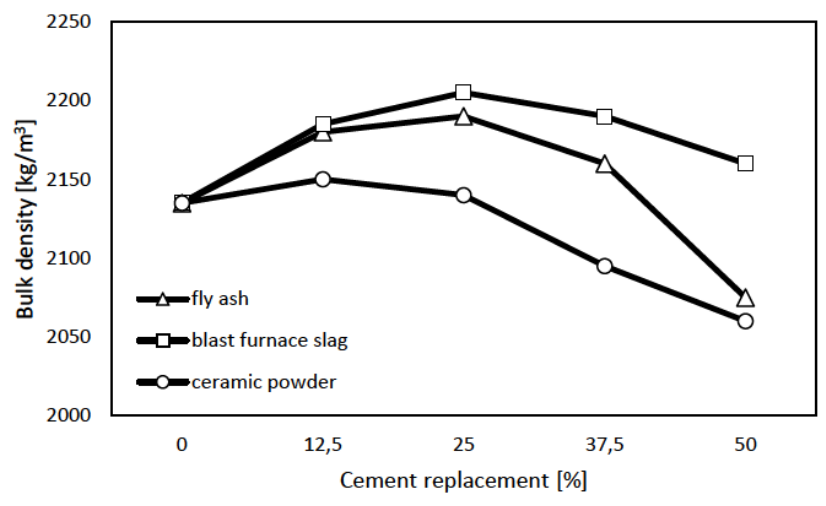

Figure 2: Bulk density of studied mixtures after 90 days $\left[\mathrm{kg} / \mathrm{m}^{3}\right]$.

tion, the lowest values; this was coupled with the effect of the increased content of air in the mixture and replacement of cement.

The detailed results for the mechanical properties after freeze-thaw cycling for selected time intervals for the studied mixtures are summarized in Table 3. There is an obvious rapid variation in the mechanical properties of the control mixture according to the type of cement used. The use of fly ash led to an improvement in the mechanical properties; however, there is a noticeable effect of time; after 28 days of curing, the mixture with $12.5 \%$ replacement exhibited similar properties to the reference mixture but, after 90 days, the properties of the mixture with $25 \%$ fly ash were already at a similar level to the control mixture; moreover, the mixture with a smaller content of fly ash had better mechanical properties. For the values obtained after 90 days, replacement by $25 \%$ fly ash seems to be optimal, because an additional increase in the replacement did not lead to a significant improvement.

The mechanical properties of mixtures with blast furnace slag did not exhibit rapid evolution over time; however, an increase in the flexural strength was recorded. Relatively low values of the compressive strength correspond with the results of non-destructive testing, indicating a larger content of technological pores in the mixture. In general, these results are similar after 28 and 90 days.

The addition of ceramic powder led to a gradual decrease in the mechanical properties, predominantly caused by the increased addition of water. The improvement of mechanical properties in time was, however, infinitesimal; after 90 days, the mixture with 50\% replacement exhibited compressive strength of about $50 \%$ of value for the control mixture. On the other hand, ceramic powder exhibited similar properties as blast furnace slag.

After 28 and 90 days, the studied mixtures were subjected to freeze-thaw cycling. Detailed results for the mechanical properties are given in Table 3. The index of frost resistance was monitored on the decay of the flexural strength after 50 cycles; however, the individual results for the compressive strength are very interesting. It is obvious that, during freeze-thaw cycling, an increase in the compressive strength was recorded for blast furnace slag and ceramic powder. This is probably due to the regime of curing under laboratory conditions; however, it is evident that addition of water, even during the freezing test, stimulated hydration of the binding system. These findings confirm the previous results $[7,45,46]$. Nevertheless, for technical practice, the relevant parameters are the residual values of the flexural strength after 90 days; the final relative values are depicted in Figure 3. There is an evident effect of increased water to cement binder ratio for mixtures with 25 and $37.5 \%$ of fly ash. The use of ceramic powder led to a gradual deterioration in the samples. On the basis of the frost resistance, we can observe a significant increase for $12.5 \%$ replacement by blast furnace slag and fly ash. This increase formed a reserve for an additional increase in the replacement level, which, for blast furnace slag, contributed to a frost resistance index for $25 \%$ replacement nearly equal to that for the control mixture. However, the need for additional mixing water in the mixture with $25 \%$ fly ash caused a noticeable increase in the capillary porosity, which negatively affected the final frost resistance. This sudden decrease is clearly visible in Figure 3. An additional increase in the cement replacement caused a dramatic deterioration, which is clearly apparent in the results for the non-destructive testing in Table 3. In terms of the durability assessment, ceramic powder is not suitable for this type of application; however, it is necessary to emphasize that the studied binding systems were free of modification agent such as plasticizers.

The progress of hydration over time was monitored by thermogravimetry (Figures 4-9). It is obvious that the employed blast furnace slag exhibited very low develop-

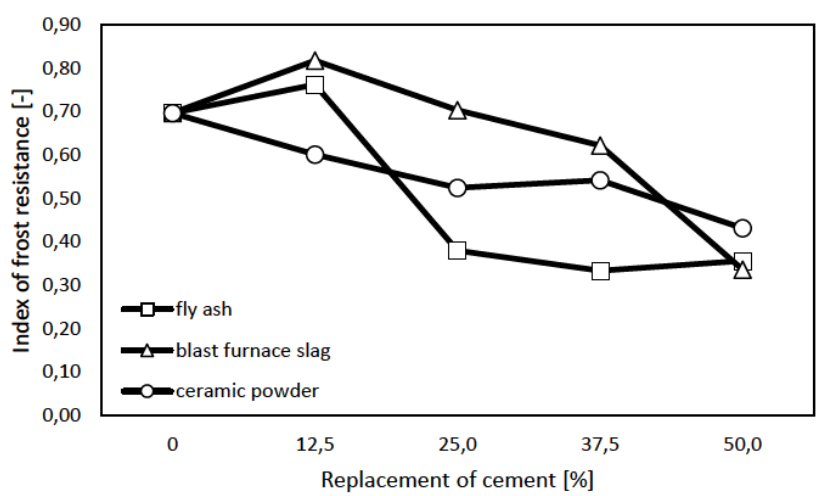

Figure 3: Index of frost resistance after 90 days and 50 freeze-thaw cycles. 
Table 3: Detailed results of mechanical properties of studied mixtures during freeze-thaw cycling.

\begin{tabular}{|c|c|c|c|c|c|c|c|c|c|c|}
\hline \multirow[t]{3}{*}{ Age } & \multirow[t]{3}{*}{ Mixture } & \multicolumn{3}{|c|}{$\begin{array}{l}\text { Flexural strength } \\
{[\mathrm{MPa}]}\end{array}$} & \multicolumn{3}{|c|}{$\begin{array}{c}\text { Compressive strength } \\
{[\mathrm{MPa}]}\end{array}$} & \multicolumn{3}{|c|}{$\begin{array}{l}\text { Dynamic modulus } \\
\text { of elasticity [GPa] }\end{array}$} \\
\hline & & \multicolumn{6}{|c|}{ Number of freeze-thaw cycles } & \multirow[b]{2}{*}{0} & \multirow[b]{2}{*}{25} & \multirow[b]{2}{*}{50} \\
\hline & & 0 & 25 & 50 & 0 & 25 & 50 & & & \\
\hline 28 & Ref & 6.1 & 5.3 & 4.9 & 47.9 & 48.1 & 49.0 & 48.3 & 47.2 & 41.6 \\
\hline 90 & Ref & 7.9 & 7.8 & 5.5 & 52.3 & 52.5 & 52.9 & 49.6 & 49.0 & 42.7 \\
\hline \multirow{4}{*}{28} & FA-12.5 & 7.2 & 6.1 & 3.1 & 47.8 & 44.5 & 40.3 & 48.1 & 44.2 & 34.0 \\
\hline & FA-25.0 & 5.7 & 2.8 & 2.5 & 41.3 & 35.7 & 32.7 & 48.3 & 40.9 & 29.3 \\
\hline & FA-37.5 & 5.6 & 2.3 & 1.8 & 35.2 & 24.8 & 32.7 & 48.1 & 33.6 & 22.6 \\
\hline & FA-50.0 & 4.8 & 1.5 & 1.3 & 26.8 & 21.5 & 20.4 & 37.5 & 37.9 & 12.0 \\
\hline \multirow{4}{*}{90} & FA-12.5 & 8.4 & 7.3 & 6.4 & 54.6 & 38.4 & 45.8 & 50.7 & 48.0 & 41.5 \\
\hline & FA-25.0 & 7.9 & 8.2 & 3.0 & 51.8 & 52.5 & 41.5 & 44.0 & 39.2 & 14.9 \\
\hline & FA-37.5 & 7.2 & 6.1 & 2.4 & 42.8 & 38.4 & 32.0 & 43.9 & 37.1 & 14.5 \\
\hline & $F A-50.0$ & 5.9 & 3.7 & 2.1 & 28.8 & 23.4 & 24.3 & 38.3 & 35.7 & 28.6 \\
\hline \multirow{4}{*}{28} & BS-12.5 & 6.3 & 4.4 & 4.7 & 39.8 & 45.9 & 42.0 & 41.1 & 20.9 & 13.7 \\
\hline & BS-25.0 & 5.4 & 4.3 & 3.6 & 34.0 & 34.8 & 37.1 & 38.6 & 11.0 & 17.7 \\
\hline & BS-37.5 & 5.3 & 3.4 & 2.5 & 26.1 & 31.1 & 28.4 & 35.1 & 10.1 & 4.6 \\
\hline & BS-50.0 & 4.6 & 1.6 & 0.5 & 27.8 & 21.7 & 6.5 & 35.3 & 2.3 & 0.0 \\
\hline \multirow{4}{*}{90} & BS-12.5 & 6.8 & 7.7 & 5.6 & 38.5 & 44.7 & 42.6 & 28.5 & 18.9 & 17.9 \\
\hline & BS-25.0 & 6.4 & 5.5 & 4.5 & 35.2 & 37.8 & 36.4 & 35.3 & 15.4 & 17.5 \\
\hline & BS-37.5 & 5.9 & 4.8 & 3.6 & 27.6 & 34.5 & 31.3 & 23.9 & 20.3 & 18.5 \\
\hline & BS- 50.0 & 5.0 & 4.1 & 1.7 & 25.7 & 31.6 & 20.0 & 23.1 & 7.6 & 10.0 \\
\hline \multirow{4}{*}{28} & CP-12.5 & 7.8 & 4.3 & 2.7 & 38.5 & 40.5 & 33.6 & 40.6 & 18.9 & 10.4 \\
\hline & CP-25.0 & 6.0 & 4.3 & 2.5 & 33.2 & 36.7 & 30.1 & 39.2 & 19.1 & 8.4 \\
\hline & CP-37.5 & 5.3 & 5.2 & 3.7 & 23.2 & 30.6 & 27.3 & 34.0 & 25.6 & 15.3 \\
\hline & CP-50.0 & 3.9 & 3.9 & 1.1 & 20.3 & 26.3 & 11.6 & 33.5 & 17.6 & 0.0 \\
\hline \multirow{4}{*}{90} & CP-12.5 & 7.7 & 6.5 & 4.6 & 39.9 & 39.2 & 38.5 & 29.2 & 19.6 & 24.5 \\
\hline & CP-25.0 & 5.7 & 4.5 & 3.0 & 33.3 & 36.2 & 32.0 & 25.7 & 16.1 & 6.7 \\
\hline & CP-37.5 & 5.4 & 4.1 & 2.9 & 26.0 & 29.5 & 30.0 & 23.2 & 22.3 & 13.8 \\
\hline & CP-50.0 & 4.2 & 3.3 & 1.8 & 26.5 & 21.0 & 20.3 & 24.2 & 11.9 & 8.0 \\
\hline
\end{tabular}

ment of the hydration product compared to the other used mineral additives. All studied SCM are characterized by retarded hydration with increasing cement replacement, which is caused by the decreased content of Portlandite serving as an activator; however, the content of hydration products gradually increases over time.

The most rapid hydration, besides to the control Portland cement paste, was exhibited by those with addition of fly ash. According to the results obtained after 90 days, replacement over $37.5 \%$ is inefficient. These results correspond well to the mechanical properties. Pastes with addition of blast furnace slag exhibited relatively retarded evolution of hydration and, after 90 days, even reached the highest content of hydration products of the studied SCMs. These samples also contained the largest amount of bound water, which is often related to reduced freeze-thaw resistance due to high density [43]. This relation was not confirmed for the obtained frost resistance. The results of thermogravimetry for samples with blast furnace slag also confirmed its applicability in larger amount. On the other hand, ceramic powder exhibited the lowest activity of all the studied SCM. Its use is relevant up to $12.5 \%$. Unreacted ceramic powder increases the internal surface area, which contributes to precipitation of cement hydrates; this is obvious from the results after 24 hours. It can be concluded that the physical effect predominates for the ceramic powder.

The relationship between the index of frost resistance and the content of hydrates, or chemically bound water, excluding the water fixed in portlandite $\left(H_{\text {hyd }}\right)$, is shown in Figure 10. The frost resistance is directly proportional to the content of hydrates in the material. This finding corresponds to general knowledge of the densifying effect of hydration and its contribution to the mechanical perfor- 


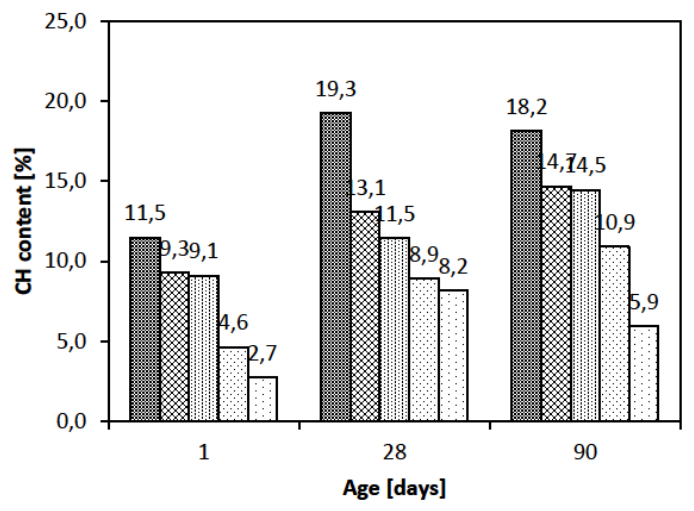

Figure 4: Development of $\mathrm{Ca}(\mathrm{OH})_{2}$ in pastes with fly ash addition in time.
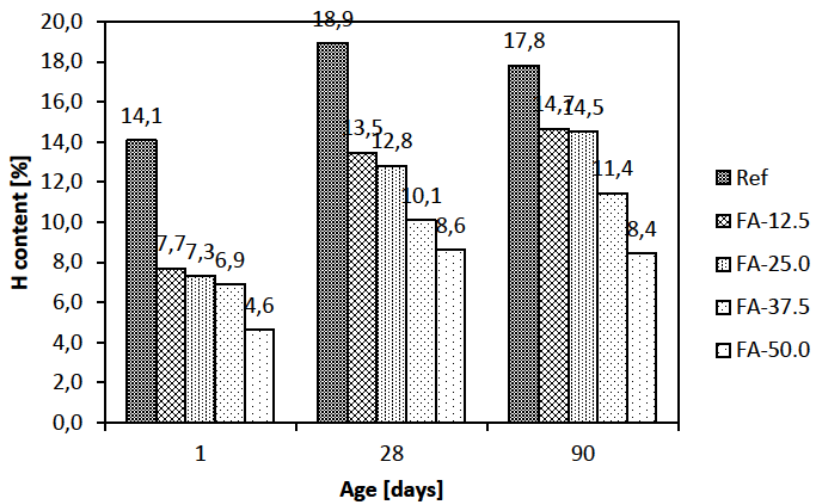

Figure 5: Development of hydrate water in pastes with fly ash addition in time.
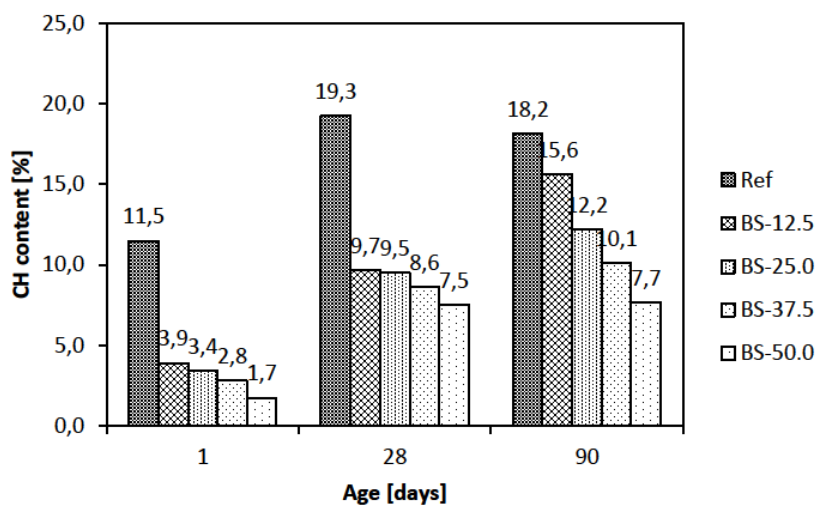

Figure 6: Development of $\mathrm{Ca}(\mathrm{OH})_{2}$ in pastes with blast furnace slag addition in time.

mance $[6,33,47]$. Inclusion of the effect of hydrates leads to a better fit with the freeze-thaw resistance in comparison with entirely chemically bound water [43]. However, the dominant factor determining the freeze-thaw resistance of concrete or its gradual deterioration is the character of the pore system. In general, the use of various SCM leads to a

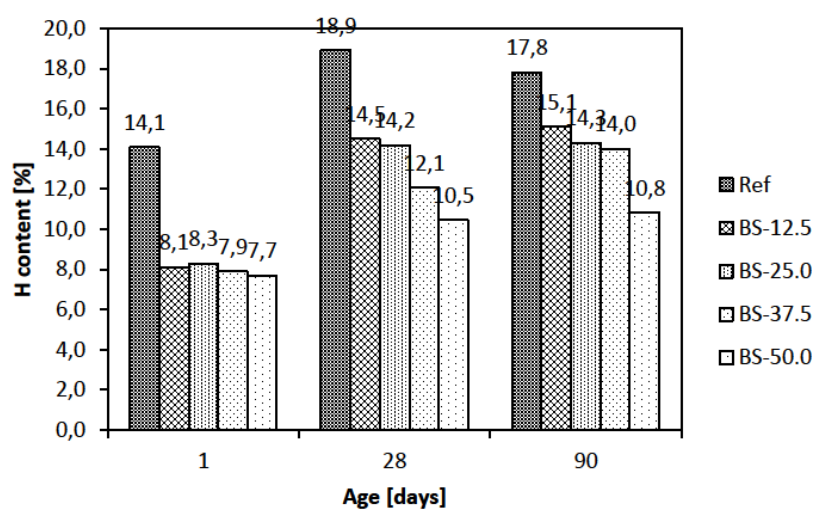

Figure 7: Development of hydrate water in pastes with blast furnace slag addition in time.

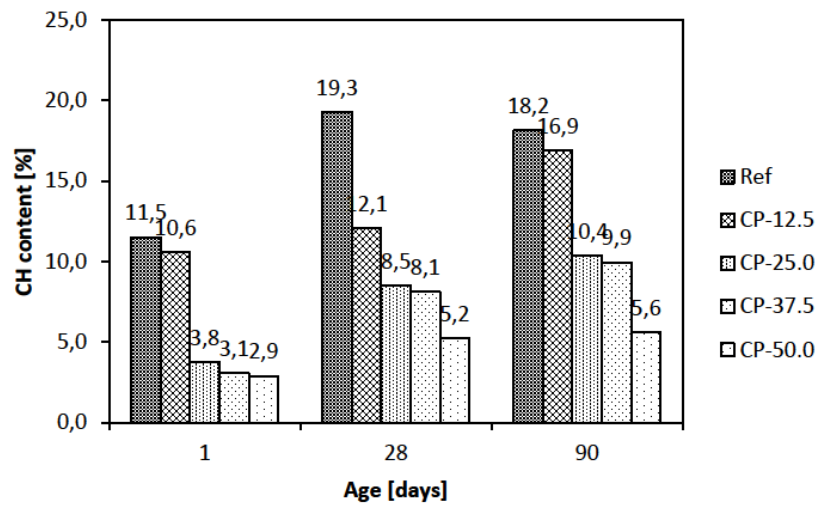

Figure 8: Development of $\mathrm{Ca}(\mathrm{OH})_{2}$ in pastes with ceramic powder addition in time.

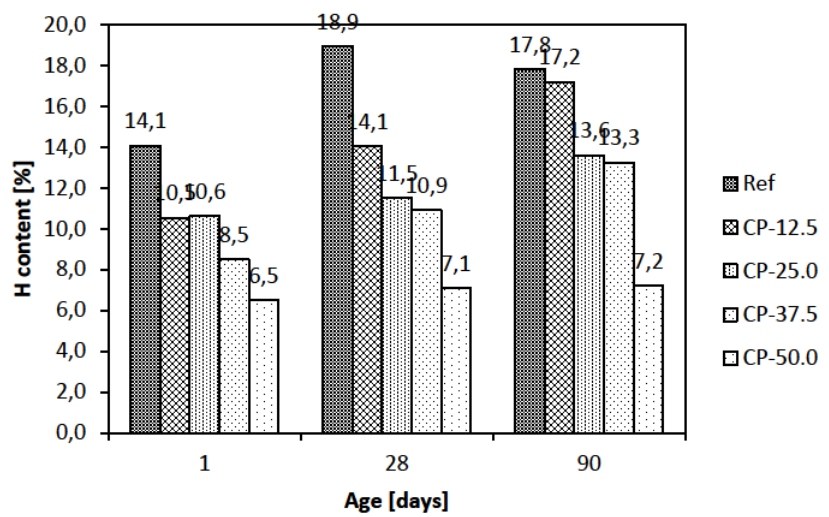

Figure 9: Development of hydrate water in pastes with ceramic powder addition in time.

reduction in the pore volume, which consequently leads to an increase in the critical temperature. This was described well by Coussy and Monteiro [28], who estimated the degree of saturation in cement-based composites incorporating silica fume. On the other hand, air-entraining conventionally used to enhance the required frost resistance 


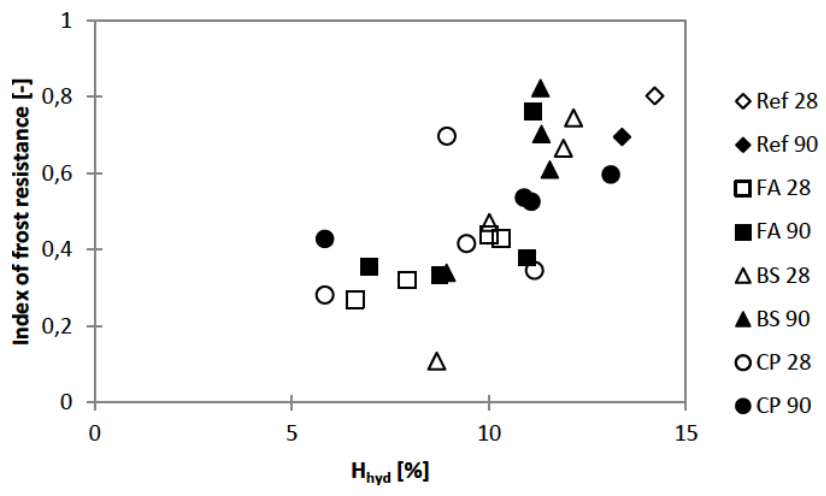

Figure 10: Relationship between Index of frost resistance (expressed by help of flexural strength after 50 cycles) and amount of water chemically bound in hydrates.

could rapidly suppress changes in the porous system resulting from the use of SCM, which was clearly described by Peng et al. [48]. Thus, hydraulic pressure is the dominating factor determining the frost resistance of cementbased materials. Comparison of the freeze-thaw resistance and the content of entrained air revealed that the air content is not able to completely explain the obtained results; ceramic powder led to the highest air content among SCM tested, but had a detrimental effect on the frost resistance. It is evident that the action of fly ash and slag cannot be attributed to the action of frost, which is well documented on the increase in the index of frost resistance. The gradual decay in the mechanical performance of mixtures with ceramic powder is caused by the low activity of this additive, confirmed by the values for chemically bounded water. Because of the high internal porosity, the damage of screed incorporating ceramic powder could be compared to that of fine grained soils $[24,49]$.

\section{Conclusions}

The performed experimental program was focused on the evaluation of cement-based screed with various SCM to find an optimal mixture with respect to the freeze-thaw resistance. The studied sets of samples were subjected to mechanical testing and determination of the frost resistance as an indicator of the durability. The studied mixtures were designed to constant consistency. The program was complemented by thermogravimetric measurement to monitor the process of hydration of the studied blended binder systems. The obtained results can be summarized as follows: I recommend using (1), (a), or (i) in text, to avoid the use of bullet points.
- The use of fly ash is beneficial up to $12.5 \%$ by weight; a further increase in the replacement led to the requirement of addition of further water, which significantly reduced the final frost resistance,

- Blast furnace slag reacted slowly but noticeably contributed to the long-term durability properties. The verified level of replacement was $25.0 \%$; however, additional curing could improve the final properties,

- A higher ratio of chemically bound water in the hydrates improved the resistance to freezing-thawing of studied screeds according to obtained the relationship or observation?,

- Ceramic powder is not a suitable mineral additive for cement-based screed without the use of a plasticizer or other modification agent because of need for the addition of water, leading to reduced frost resistance. Its effect in the hydrated paste is predominantly physical

- The content of air in fresh concrete does not necessarily improve the frost resistance. This factor is controlled by the character of the porous system and resulting hydraulic pressure during the action of frost.

The obtained results confirmed the potential of mineral additives in cement-based composites and accented the necessity of the assessment of the durability aspects. The studied ceramic powder did not confirm a potential for a practical use; nevertheless this interesting additive should be further studied in combination with other active mineral additives.

Acknowledgement: This work has been supported by Czech Science Foundation under the project No. 18-13525S and Ministry of Education, Youth and Sports under the COST project No. LTC18063.

\section{References}

[1] C. Meyer, Cement and Concrete Composites, 31 (2009) 601-605.

[2] M. Uysal, K. Yilmaz, and M. Ipek, Construction and Building Materials, 27 (2012) 263-270

[3] M. Keppert, M. Urbanová, J. Brus, M. Čáchová, J. Fořt, A. Trník, et al., Construction and Building Materials, 148 (2017) 411-418.

[4] K. De Weerdt, K.O. Kjellsen, E. Sellevold, and H. Justnes, Cement and Concrete Composites, 33 (2011) 30-38.

[5] H. Yazıcı, Construction and Building Materials, 22 (2008) 456462.

[6] D. Wang, X. Zhou, Y. Meng, and Z. Chen, Construction and Building Materials, 147 (2017) 398-406.

[7] C.-W. Chung, C.-S. Shon, and Y.-S. Kim, Construction and Building Materials, 24 (2010) 1739-1745. 
[8] E. Özbay, M. Erdemir, and H.I. Durmuş, Construction and Building Materials, 105 (2016) 423-434.

[9] Z. Giergiczny, M.A. Glinicki, M. Sokotowski, and M. Zielinski, Construction and Building Materials, 23 (2009) 2451-2456.

[10] J. Deja, Cement and Concrete Composites, 25 (2003) 357-361.

[11] G.J. Osborne, Cement and Concrete Composites, 21 (1999) 11-21.

[12] M. Drdácký, F. Fratini, D. Frankeová, and Z. Slížková, Construction and Building Materials, 38 (2013) 1117-1128.

[13] G. Baronio and L. Binda, Construction and Building Materials, 11 (1997) 41-46.

[14] Z. Pavlík, A. Trník, T. Kulovaná, L. Scheinherrová, V. Rahhal, E. Irassar, et al., International Journal of Thermophysics, 37 (2016).

[15] F. Pacheco-Torgal and S. Jalali, Construction and Building Materials, 24 (2010) 832-838.

[16] E. Navrátilová and P. Rovnaníková, Construction and Building Materials, 120 (2016) 530-539.

[17] B. Ercikdi, G. Külekci, T. Yılmaz, Construction and Building Materials, 93 (2015) 573-583.

[18] D.M. Kannan, S.H. Aboubakr, A.S. EL-Dieb, and M.M. Reda Taha, Construction and Building Materials, 144 (2017) 35-41.

[19] M.A. Glinicki, R. Jaskulski, and M. Dabrowski, Roads and Bridges - Drogi I Mosty, (2016) 21-43.

[20] CSN 73 1325: Determination of frost resistance of concrete using accelerated tests, Czech Republic (1972).

[21] R. Černý and P. Rovnaniková, Transport Processes in Concrete, Spon Press, London, (2002).

[22] P. A. Claisse, Transport Properties of Concrete, Woodhead Publishing, Cambridge, (2014).

[23] T.C. Powers, The air requirement of frost-resistant concrete, Highway Research Board Proceedings 184 (1949).

[24] K.A. Jackson and B. Chalmers, Journal of Applied Physics, 29 (1958) 1178-1181.

[25] Z. Sun and G.W. Scherer, Cement and Concrete Research, 40 (2010) 260-270.

[26] L. Liu, D. Shen, H. Chen, W. Sun, Z. Qian, H. Zhao, et al., Cement and Concrete Composites, 53 (2014) 1-9.

[27] Z. P. Bazant, J. C. Chern, A. M. Rosenberg, and J. M. Gaidis, Journal of the American Ceramic Society, 71 (1988) 776-783.

[28] O. Coussy and P.J.M. Monteiro, Cement and Concrete Research, 38 (2008) 40-48.

[29] L. Liu, S. Wu, H. Chen, and Z. Haitao, Cold Regions Science and Technology, 106-107 (2014) 141-152.

[30] M.J. Setzer, Journal of Colloid and Interface Science, 235 (2001) 170-182.
[31] J. Zhou and D. Li, Cold Regions Science and Technology, 72 (2012) 43-49.

[32] M.J. Setzer and R. Auberg, Damages caused by freeze-thaw cycles with de-icing salt Topical results - Recommendations for practice, Concrete Precasting Plant and Technology, 72 (2006) 96-97.

[33] M. Balapour, A. Joshaghani, and F. Althoey, Construction and Building Materials, 181 (2018) 27-41.

[34] K. Behfarnia and N. Salemi, Construction and Building Materials, 48 (2013) 580-584.

[35] P. Reiterman, European Journal of Environmental and Civil Engineering, (2018) 1-14.

[36] E. Özbay, O. Karahan, M. Lachemi, K.M.A. Hossain, and C.D. Atis, Composites Part B: Engineering, 45 (2013) 1384-1390.

[37] CSN EN 1015-3: Methods of test for mortars for masonry - Determination of consistence of fresh mortar (by flow table), Czech Republic (2000).

[38] CSN EN 12350-7: Testing fresh concrete - Part 7: Air content Pressure methods, Czech Republic (2009).

[39] CSN 731322 - Determination of frost resistance of concrete, Czech Republic (2003).

[40] M. Hora and P. Reiterman, Revista Romana de Materiale, 46 (2016) 327.

[41] CSN 73 1371: Testing of hardened concrete - Determination of ultrasonic pulse velocity, Czech Republic (2005).

[42] K. De Weerdt, M.B. Haha, G. Le Saout, K.O. Kjellsen, H. Justnes, and B. Lothenbach, Cement and Concrete Research, 41 (2011) 279-291.

[43] V. Bílek, P.Mec, L. Zidek, and T. Moravec, Cement Wapno Beton, 2015 (2015) 72-78.

[44] K. Polozhiy, J.A. Siddique, and P. Reiterman, Materials Science Forum, 824 (2015) 61-64.

[45] M. Sahmaran, G. Yildirim, and T.K. Erdem, Cement and Concrete Composites, 35 (2013) 89-101.

[46] L. Soriano, J. Monzó, M. Bonilla, M.M. Tashima, J. Payá, and M.V. Borrachero, Cement and Concrete Composites, 42 (2013) 41-48.

[47] P. Zhang, F.H. Wittmann, M. Vogel, H.S. Müller, and T. Zhao, Cement and Concrete Research, 100 (2017) 60-67.

[48] G.-F. Peng, Q. Ma, H.-M. Hu, R. Gao, Q.-F. Yao, and Y.-F. Liu, Construction and Building Materials, 21 (2007) 1034-1039.

[49] G.W. Scherer, Cement and Concrete Research, 29 (1999) 13471358. 